\title{
Oficinas de Biotecnologia para o Ensino Médio: Antioxidantes, a Fonte da
}

juventude?

\author{
Biotechnology workshops for secondary education: antioxidants, the fountain of youth?
}

\begin{abstract}
Diorge Jônatas Marmitt ${ }^{1 *}$, Dalana Faleiro ${ }^{1}$, Débora Mara Kich ${ }^{1}$, Juliano Leipelt ${ }^{1}$, Natália de Oliveira Flores ${ }^{2}$,Tamara Baldasso ${ }^{2}$, Sheila Mariele Immich ${ }^{2}$, Márcia Inês Goettert ${ }^{1}$
\end{abstract}

${ }^{1}$ Cell Culture Laboratory, Postgraduate Program in Biotechnology, University Center UNIVATES, Lajeado/RS, Brazil

${ }^{2}$ Cell Culture Laboratory, Center of Biological and Health Sciences, University Center UNIVATES, Lajeado/RS, Brazil

*e-mail: diorgemarmitt@yahoo.com.br

Support: FAPERGS, CNPq and CAPES.

\begin{abstract}
Theory and practice about biotechnology-related issues have been topics of workshops for students and teachers of the Post Graduate in Biotechnology UNIVATES to secondary education students. We held ten different workshops aimed at the food production and health, among which stands out in this study, the workshop entitled "Antioxidants: the fountain of youth?", which evaluated the antioxidant potential of natural juice orange select and pearl pineapple. Previously, a protocol was structured on the practice, which aimed to evaluate the juice antioxidant potential of the fruit orange select and pearl pineapple, which was compared with the antioxidant reference compound, ascorbic acid, with adaptations according to spectrophotometric method in vitro DPPH. The workshops about antioxidants have 180 minutes duration and have been taught by three monitors responsible for assisting students throughout the activity. The workshops involved 388 students from seven schools in six municipalities of Taquari-RS Valley, and the workshop about antioxidants had 62 participants. This activity aimed to promote interaction and diffusion of knowledge among students of higher education and secondary education.
\end{abstract}

\section{Keywords: Ascorbic Ácid; Education, Primary and Secondary; Free Radicals.}

\section{Resumo}

Teoria e prática sobre assuntos relacionados à Biotecnologia foram temas de oficinas realizadas por discentes e docentes do Programa de Pós-Graduação em Biotecnologia da UNIVATES a estudantes de Ensino Médio. Foram ministradas dez diferentes oficinas voltadas à produção de alimentos e à saúde, entre as quais destaca-se, neste estudo, a oficina intitulada "Antioxidantes: a fonte da juventude?", que avaliou o potencial antioxidante do suco natural da laranja seleta e do abacaxi pérola. Previamente, foi estruturado um protocolo sobre a prática, a qual objetivou avaliar o potencial antioxidante do suco das frutas laranja seleta e abacaxi pérola, o qual foi comparado com o composto antioxidante de referência, ácido ascórbico, com adaptações segundo o método espectrofotométrico in vitro DPPH. As oficinas sobre antioxidantes tiveram duração de 180 minutos e foram ministradas por três monitores responsáveis por auxiliar os alunos durante toda a atividade. As oficinas envolveram 388 alunos de sete escolas de seis municípios do Vale do Taquari-RS, sendo que a oficina sobre antioxidantes contou com 62 participantes. Tal atividade buscou promover a interação e difusão de conhecimento entre alunos de Ensino Superior e de Ensino Médio.

Palavras-chave: Ácido Ascórbico; Ensino Fundamental e Médio; Radicais Livres. 


\section{Ficha da atividade desenvolvida}

\begin{tabular}{|l|l|}
\hline Título & $\begin{array}{l}\text { Oficinas de Biotecnologia para o Ensino Médio: Antioxidantes, a Fonte da } \\
\text { juventude? }\end{array}$ \\
\hline Público-alvo & Alunos de Ensino Médio. \\
\hline $\begin{array}{l}\text { Disciplinas } \\
\text { relacionadas }\end{array}$ & Bioquímica; Biologia Molecular e Celular; Fisiologia Humana; Biotecnologia. \\
\hline $\begin{array}{l}\text { Obetivos } \\
\text { educacionais }\end{array}$ & Aproximar estudantes do Ensino Médio com a realidade do Ensino Superior. \\
\hline $\begin{array}{l}\text { Justificativa } \\
\text { de uso }\end{array}$ & $\begin{array}{l}\text { Estratégia de ensino por meio da realização de oficinas práticas, mostrando aos } \\
\text { alunos de Ensino Médio benefícios dos antioxidantes na saúde. }\end{array}$ \\
\hline $\begin{array}{l}\text { Conteúdos } \\
\text { trabalhados }\end{array}$ & Atividade antioxidante. \\
\hline $\begin{array}{l}\text { Estimated } \\
\text { duration }\end{array}$ & 6 h/a. \\
\hline
\end{tabular}




\section{Introdução}

O Programa de Pós-Graduação em Biotecnologia (PPGBiotec) do Centro Universitário UNIVATES, criado em 2012, tem como objetivo formar recursos humanos qualificados, capazes de gerar e disseminar conhecimentos científicos e tecnológicos voltados à Biotecnologia nas áreas de produção de alimentos e saúde humana e animal, com uma visão integrada das perspectivas socioambientais e econômicas [1].

A fim de aproximar estudantes do Ensino Médio com a realidade do Ensino Superior, e para mostrar que a Biotecnologia está relacionada com o cotidiano de todos, são oferecidas, gratuitamente, por discentes e docentes do Programa, atividades denominadas "Oficinas de Biotecnologia para o Ensino Médio".

Em 2015, durante uma semana no mês de junho, nos turnos da manhã e noite, ocorreu a terceira edição da atividade. Foram ministradas dez diferentes oficinas voltadas a temas da Biotecnologia, especialmente à produção de alimentos e à saúde humana $\mathrm{e}$ animal. Participaram sete escolas de seis municípios do Vale do Taquari-RS.

Nessas oficinas, que ocorrem desde 2013, são ministradas atividades teóricas e práticas, abordando diferentes temas ligados aos projetos de pesquisa vinculados ao PPGBiotec. As oficinas oportunizam o contato de estudantes do Ensino Médio com diferentes áreas da Biotecnologia, propiciando aprendizagem e aproximação destes alunos com pesquisas desenvolvidas na instituição, auxiliando na escolha de uma possível futura carreira profissional.

Em 2015, na terceira edição da atividade, foram desenvolvidas oficinas abordando os seguintes temas: infertilidade e biotecnologia aplicada à saúde do homem; correção da acidez de solos $(\mathrm{pH})$; biotecnologia e produção de alimentos derivados do leite; biotransformação de resíduos orgânicos em minhocários alternativos; visualização de DNA através do produto da Reação em Cadeia da Polimerase (PCR); aplicação de proteínas e micro-organismos no dia a dia; técnica de extração de DNA e suas aplicações; identificação de espécies vegetais; novas tecnologias na agroecologia: inovação em controle biológico; e antioxidantes, que é o foco deste trabalho.

Tal atividade é valorizada pela Coordenação de Aperfeiçoamento de Pessoal de Nível Superior (CAPES), órgão que regulamenta os Programas de Pós-Graduação no Brasil. O item Inserção Social do documento da área de Biotecnologia [2], destaca à valorização de ações de extensão, promoção de feiras de ciências e oficinas com efetivo envolvimento do corpo docente e discente. Assim, a CAPES incentiva o contato de alunos de escolas públicas do Ensino Fundamental e Médio com o Ensino Superior, o que 
também contribui para a melhoria da Educação Básica.

Dentre os temas desenvolvidos na atividade, aborda-se a oficina que tratou sobre antioxidantes. Assim, constitui-se o objetivo do presente trabalho, qual seja descrever a experiência da realização da oficina sobre antioxidantes bem como apresentar e analisar os resultados obtidos pelos alunos durante a oficina.

\section{Metodologia}

A oficina que é destacada neste artigo, intitulada "Antioxidantes: Fonte da Juventude?", foi desenvolvida e ministrada por discentes e docentes do projeto de pesquisa "Efeito anti-inflamatório, anticarcinogênico e toxicidade de extratos vegetais em cultura de células". Tal atividade ocorreu em dois turnos no laboratório de Bioquímica da UNIVATES: turno da noite do dia 15 de junho de 2015 e turno da manhã do dia 17 de junho de 2015. Participaram da oficina, alunos do Ensino Médio da Escola Estadual de Ensino Médio Souza Doca, de Muçum-RS.

Previamente, foi estruturado pelo grupo que ministrou a oficina, um protocolo sobre a prática, a qual objetivou avaliar o potencial antioxidante do suco das frutas laranja seleta e abacaxi pérola, adquiridas comercialmente. Esse potencial foi comparado com o composto antioxidante de referência, ácido ascórbico (vitamina $C, \mathrm{C}_{6} \mathrm{H}_{8} \mathrm{O}_{6}$ ), com adaptações segundo o método espectrofotométrico in vitro DPPH (2,2-difenil-1-picrilhidrazil). Este é baseado na captura do radical livre DPPH por antioxidantes, produzindo um decréscimo da absorbância do radical [3].

Nesse protocolo, constou uma sucinta explicação sobre compostos antioxidantes além do roteiro detalhado da técnica que foi realizada pelos alunos. Ambas as oficinas sobre antioxidantes tiveram duração de 180 minutos e foram ministradas por três monitores responsáveis por auxiliar os alunos durante toda a atividade.

Primeiramente, os monitores explanaram durante aproximadamente 30 minutos acerca do tema que seria abordado. Explicaram que a produção de radicais livres e a oxidação de biomoléculas são processos comuns e essenciais, continuamente produzidos no organismo. Estes radicais livres em concentrações fisiológicas desempenham funções essenciais na proteção do organismo, porém, em concentrações elevadas estão associados à deficiência no sistema protetor, ocasionando o chamado "estresse oxidativo", o que acarreta em um processo de envelhecimento precoce das células [4]. Citou-se algumas fontes endógenas de radicais livres, como as mitocôndrias, inflamação, peroxissomos além de enzimas como xantina oxidase, citocromo P450-oxidase. Da 
mesma forma, exemplificou-se as fontes exógenas como o estresse, poluição, tabaco, álcool, agrotóxicos e radiações. Nesse sentido, a busca por compostos antioxidantes capazes de neutralizar radicais livres, os quais podem retardar ou mesmo prevenir danos oxidativos, é cada vez mais frequente [5].

Sendo assim, mencionou-se que a vitamina $C$ é um dos principais compostos antioxidantes, fornecendo suporte ao sistema imunológico, e auxiliando a neutralizar os radicais livres nas células. Mencionou-se ainda, as principais fontes de vitamina $\mathrm{C}$ para o consumo [6]. Assim, nivelaram-se os conhecimentos prévios dos alunos participantes da oficina, e na sequência, os monitores explicaram como seria realizada a prática.

Inicialmente, os alunos prepararam em tubos de ensaio de $15 \mathrm{~mL}$, as diluições do ácido ascórbico (AA) a partir da solução mãe de $1 \mathrm{mg} / \mathrm{mL}$, diluído em metanol. Foram realizadas diluições seriadas nas concentrações de 100, 50, 25, 12,5 e 6,25 $\mu \mathrm{g} / \mathrm{mL}$ (Figura 1).

- $\quad$ No primeiro tubo, os alunos adicionaram $3600 \mu \mathrm{L}$ de $\mathrm{H}_{2} \mathrm{O}+400 \mu \mathrm{L}$ da solução mãe de AA e homogeneizaram bem;

- $\quad$ Nos demais tubos, pipetaram $2 \mathrm{~mL}$ de $\mathrm{H}_{2} \mathrm{O}$;

- Transferiram $2 \mathrm{~mL}$ da solução do tubo A para o tubo B e homogeneizaram bem;

- Passaram $2 \mathrm{~mL}$ da solução do tubo B para o tubo C, e assim procederam sucessivamente com as demais diluições;

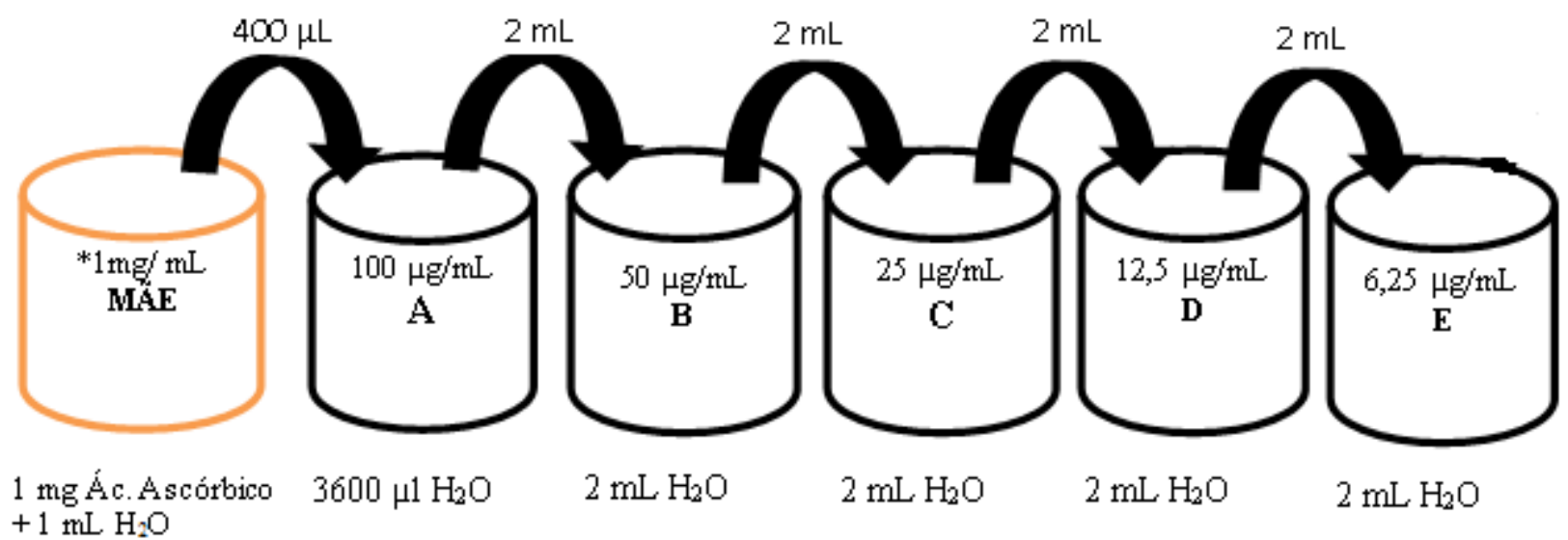

Figura 1. Diluições do AA a partir da solução mãe de $1 \mathrm{mg} / \mathrm{mL}$. Fonte: Autor.

O DPPH já estava previamente preparado, tendo sido dissolvido $0.004 \mathrm{~g}$ do composto em $100 \mathrm{~mL}$ de álcool metílico [3]. Após terem realizado as diluições, os estudantes prepararam as seguintes soluções para cada concentração, tanto do AA, como dos sucos naturais:

- Em tubos de ensaio, separadamente, adicionaram $500 \mu \mathrm{L}$ de cada diluição da 
curva do ácido ascórbico + $1000 \mu \mathrm{L}$ de DPPH (Figura 2);

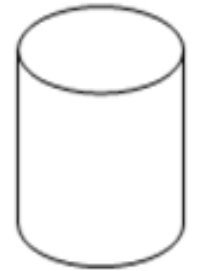

$500 \mu \mathrm{I}$ TUBO A

$+1000 \mu \mathrm{L}$ DPPH

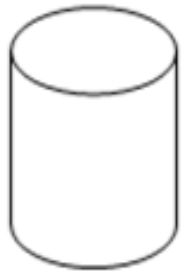

$500 \mu \mathrm{l}$ TUBO B

$+1000 \mu \mathrm{L}$ DPPH

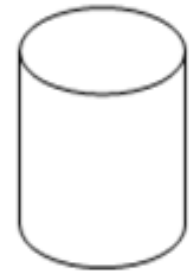

$500 \mu \mathrm{I}$ TUBO C $+1000 \mu \mathrm{LDPPH}$

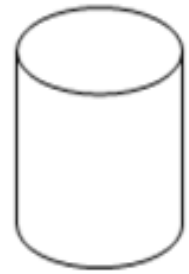

$500 \mu \mathrm{l}$ TUBO D $+1000 \mu \mathrm{L}$ DPPH

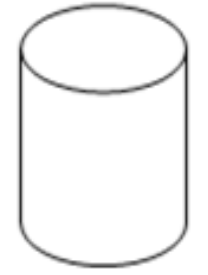

$500 \mu \mathrm{I}$ TUBOE $+1000 \mu \mathrm{L}$ DPPH

Figura 2. Diluições seriadas das amostras da curva de AA. Fonte: Autor.

Com os sucos, tanto de laranja, como de abacaxi, foram testadas apenas duas concentrações: 25 e $12,5 \mu \mathrm{g} / \mathrm{mL}$.

- Da mesma forma, também em tubos de ensaio distintos, adicionaram $500 \mu \mathrm{L}$ de cada diluição do suco de cada fruta (separadamente) + $1000 \mu \mathrm{L}$ de DPPH (Figura 3).
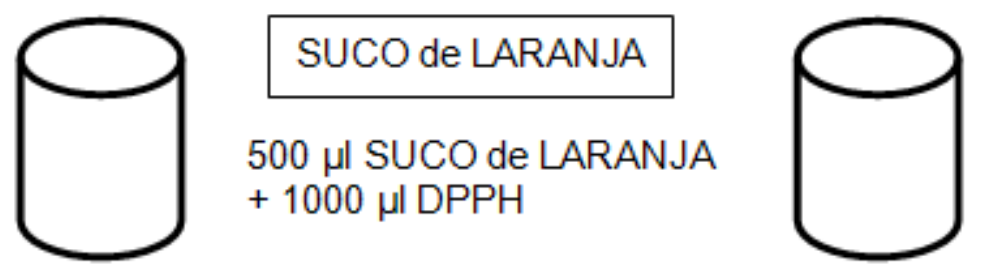

\section{SUCO de ABACAXI}

$500 \mu \mathrm{l}$ SUCO de ABACAXI

$+1000 \mu \mathrm{l}$ DPPH

Figura 3. Diluições das amostras dos sucos de laranja e abacaxi. Fonte: Autor.

Em seguida, as amostras foram incubadas à temperatura ambiente durante $30 \mathrm{~min}$. Decorrido o tempo de incubação, foi procedida a leitura das amostras $(1 \mathrm{~mL}$ de cada diluição do AA e posteriormente das amostras dos sucos) em espectrofotômetro em comprimento de onda de 517 nanômetros $(\mathrm{nm})$.

Os dados obtidos, foram analisados estatisticamente utilizando-se o programa GraphPad Prism® (versão 5.0 GraphPad Software, Inc.) e expressos como média \pm SEM (erro padrão da média). Valores de $p<0.05$ foram considerados significativos. 


\section{Resultados}

Esta edição das Oficinas de Biotecnologia para o Ensino Médio contou com a participação de 388 estudantes, destes, 62 participaram das oficinas sobre antioxidantes.

Os resultados demonstrados aos alunos foram tanto visuais, por meio da mudança de coloração após a redução do radical DPPH, como também com os valores obtidos após a leitura das amostras em espectrofotômetro. Quanto menor a absorbância encontrada, mais transparente ficou a tonalidade da solução e, assim, maior foi o potencial de redução do radical livre DPPH pela amostra analisada (Figura 4).

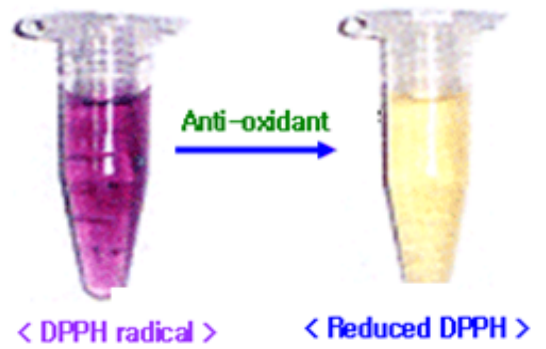

Figura 4. Redução do radical DPPH. Fonte: Mensor et al., 2001.

A avaliação do potencial antioxidante foi fundamentada na redução do DPPH. O valor da atividade inibitória $\left(\mathrm{IC}_{50}\right)$ das amostras dos sucos e do padrão de $\mathrm{AA}$ foi determinado como base comparativa do potencial antioxidante. Os resultados obtidos para as amostras e para o padrão estão expressos nas Figuras 5 (atividade antioxidante) e $6\left(\mathrm{IC}_{50}\right)$.

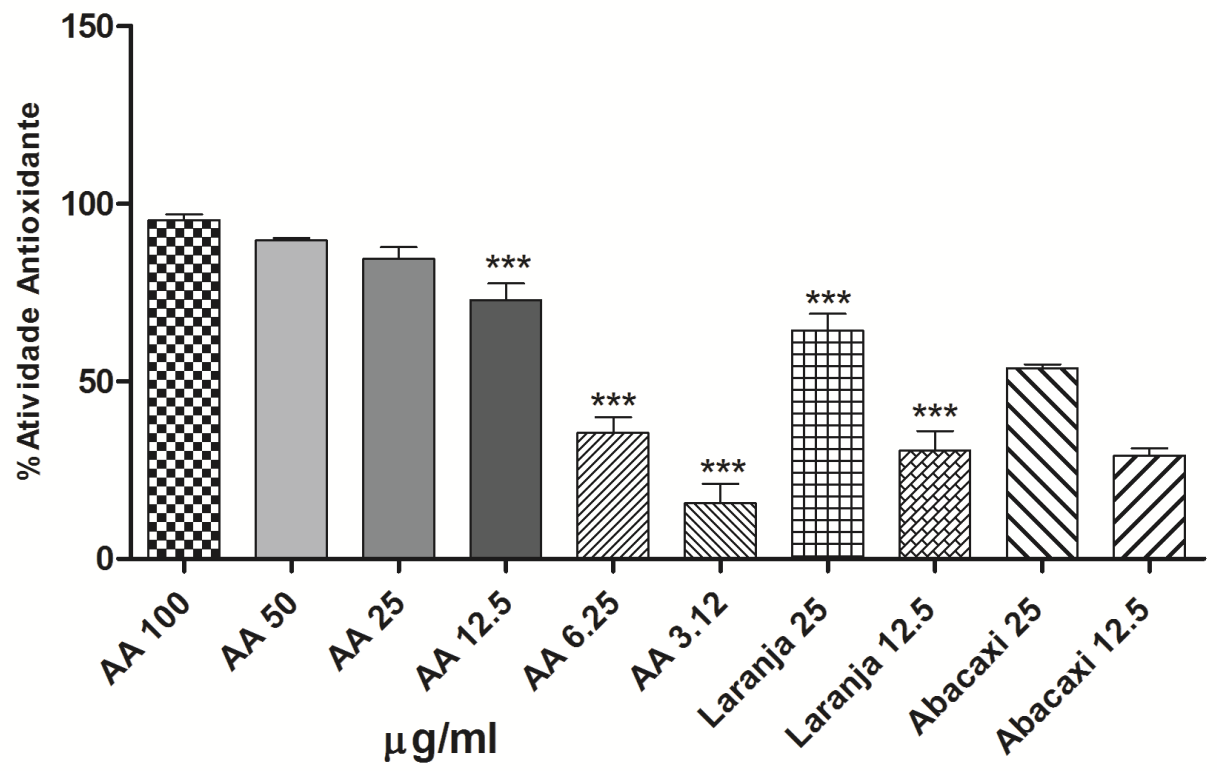

Figura 5: Percentagem da atividade antioxidante das concentrações do Ácido Ascórbico (AA) e dos sucos de Laranja e Abacaxi. AA 100: 95,39 ( $\pm 1,15)$; AA 50: 89,6 $( \pm 0,47)$; AA 25: 84,43 $( \pm 2,36)$; AA 12,5: $72,83( \pm 3,34)$; AA $6,25: 35,49$ $( \pm 3,03)$; Laranja 25: 64,29 ( \pm 3.31$)$; Laranja 12,5: 30,47 ( $\pm 3,91)$; Abacaxi 25: 53,61 ( $\pm 0,8)$; Abacaxi 12,5: 29,05 ( $\pm 1,07)$. Os valores foram expressos em duplicata, referente as duas oficinas. ${ }^{* *} p<0.01$. ${ }^{* *} p<0.001$. 
Com análises in vitro, verificou-se que as amostras do suco de laranja apresentaram um percentual de atividade antioxidante ligeiramente maior em comparação as amostras do suco de abacaxi (Figura 5).

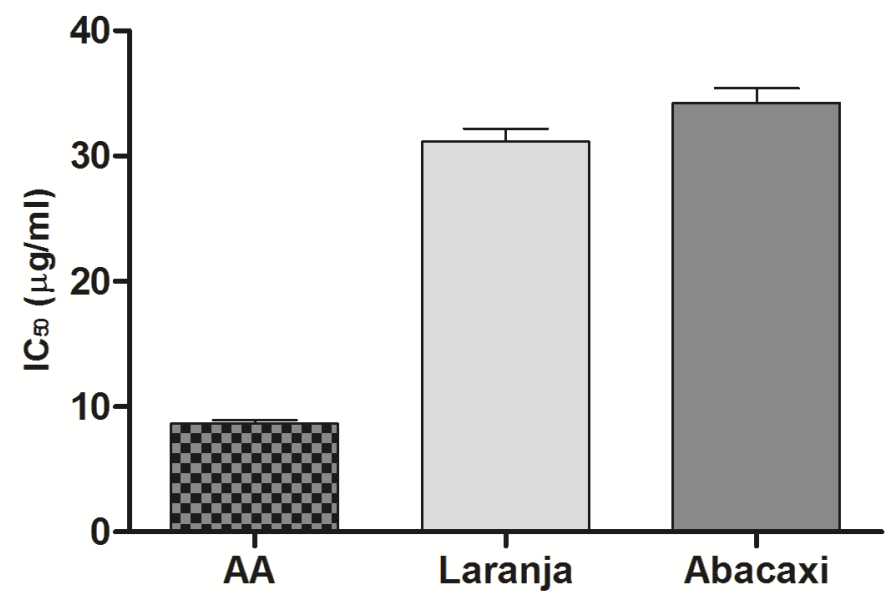

Figura 6: Atividade Antioxidante das concentrações do Ácido Ascórbico (AA) e dos sucos de Laranja e Abacaxi, observando os seguintes valores de $I_{50}$ : AA: $8,65 \mu \mathrm{g} / \mathrm{ml}( \pm 0,19)$; Laranja: $31,14 \mu \mathrm{g} / \mathrm{ml}( \pm 0,74)$; Abacaxi: $34,23 \mu \mathrm{g} / \mathrm{ml}( \pm 0,85)$. Os valores foram expressos em duplicata, referente as duas oficinas.

A atividade inibitória $\left(\mathrm{IC}_{50}\right)$ do suco de laranja (Figura 6$)$ foi melhor do que quando comparada com a amostra do abacaxi. Isso evidencia que a laranja apresentou melhor potencial antioxidante em relação ao abacaxi.

\section{Discussão}

O modelo de oficinas sobre Biotecnologia voltadas para o Ensino Médio é inovador em Programas de Pós-Graduação. Como já mencionado, conta com o incentivo da CAPES, evidenciando a inserção social do Programa na região do Vale do Taquari/RS.

O título "Antioxidantes: Fonte da Juventude?" despertou a curiosidade, considerando que é um tema de visibilidade na mídia. Percebeu-se que os estudantes possuíam noções sobre os benefícios dos antioxidantes na saúde, pois tratam-se de substâncias que previnem danos celulares ocasionados pelos radicais livres, estabilizam a molécula, evitando assim danos a outras células [7]. Estes benefícios para a saúde são principalmente devidos à presença de compostos fitoquímicos, como polifenóis, carotenoides e vitaminas E e C [8].

Vale destacar que o papel dos mecanismos de defesa antioxidantes é de neutralizar radicais livres, evitando danos oxidativos a proteínas, lipídios e ao DNA, que cumulam durante a vida, promovendo processo de envelhecimento da pele. Doenças degenerativas têm sido ainda relacionadas com a patogênese do câncer $[9,10]$. Ao serem 
questionados acerca do tema, alguns alunos tinham este conhecimento e suas respostas eram condizentes.

Sendo assim, os monitores ressaltaram que fontes naturais de agentes antioxidantes, como compostos fenólicos, flavonoides, esteroides e taninos, são cada vez mais pesquisadas. Por esta razão, há um crescente interesse em extrair tais constituintes de produtos naturais e usá-los como antioxidantes naturais, aliado ao fato de que estudos apontam que os antioxidantes sintéticos como o butil-hydroxyanisole (BHA) e butilhidroxitolueno (BHT), sejam tóxicos [11-13].

Já se sabe que tanto a laranja como o abacaxi são ricos em vitamina $C$, e isto foi afirmado nas respostas dos alunos durante as oficinas e confirmado com os resultados dos ensaios. Lu et al. (2014) [14] mencionam que a capacidade antioxidante do abacaxi está relacionada com o conteúdo de compostos fenólicos, além de polifenóis como os flavonoides.

Pisoschi e colaboradores (2009) [15] também testaram o potencial antioxidante através do método de DPPH em amostras comerciais de sucos de laranja. Os resultados foram os esperados, atividade antioxidante nas amostras analisadas.

Um estudo desenvolvido por Crowe \& Murray (2013) [16], avaliou a capacidade antioxidante do suco natural $(100 \%)$ de quatro tipos de frutas, uva, maçã, laranja e abacaxi, comparando com os sucos de marcas comerciais. Avaliada através do método de DPPH, a atividade antioxidante dos sucos naturais foi entre $23 \%$ a $54 \%$ maior do que a atividade média de antioxidantes dos respectivos sucos comerciais.

Tais pesquisas corroboram os já esperados resultados obtidos na prática realizada pelos estudantes. Optou-se em utilizar tais espécies por serem frutas cítricas com propriedades antioxidantes já conhecidas. Assim, foi possível, aos alunos, identificarem e determinarem a atividade antioxidante ao observarem a mudança de coloração das amostras após o período de incubação, e com os resultados da leitura das absorbâncias, concluir que as frutas testadas apresentam alta quantidade de antioxidantes e desta forma são benéficas para a saúde.

O impacto na aprendizagem dos alunos foi positivo, tendo sido possível observar que o trabalho em grupo oportunizou momentos de aprendizagem e discussão acerca desta estratégia de ensino centrada na autonomia do aluno. Neste contexto, a aprendizagem colaborativa, por meio do trabalho em grupo e pela troca entre os pares, resulta em conhecimento mútuo [17]. É preciso considerar, ainda, que a oficina se caracteriza como uma estratégia do fazer pedagógico, criando um espaço de construção 
e principalmente reconstrução do conhecimento teórico agora aplicado na prática [18]. Tal ambiente foi perceptível nas oficinas, pois se constituem num instrumento didático que dinamiza as aulas tradicionais, possibilitando maior interação entre os discentes, bem como entre o docente e os discentes, fomentando a autonomia dos alunos.

\section{Conclusão}

A partir dos resultados, conclui-se que as Oficinas de Biotecnologia estão se consolidando no PPGBiotec, em virtude da boa aceitação das escolas e principalmente, do número elevado de estudantes participantes. As oficinas propiciam momentos de aprendizagem e aproximação de estudantes do Ensino Médio com a realidade do Ensino Superior.

Os resultados sobre a atividade antioxidante realizada pelos estudantes corroboram o que a literatura menciona sobre as frutas avaliadas, as quais apresentam potencial antioxidante, muito em função de compostos como a vitamina $\mathrm{C}$.

As oficinas oportunizam o contato de estudantes do Ensino Médio com diferentes áreas da Biotecnologia, propiciando aprendizagem e aproximação destes alunos com pesquisas desenvolvidas na instituição, auxiliando na escolha de uma possível futura carreira profissional.

\section{Referências}

[1] Univates. Programa de Pós-Graduação - Mestrado Biotecnologia. 2015. Disponível em: < http://www.univates.br/ppgbiotec/conheca-o-ppgbiotec > Acesso em: julho de 2015.

[2] CAPES. Documento de área - Biotecnologia. 2013. Disponível em: < http://www.capes.gov.br/images/stories/download/avaliacaotrienal/Docs_de_area/Biotecnologia_doc_area_e comiss \%C3\%A3o_block.pdf > Acesso em: julho de 2015.

[3] Mensor FS, Menezes CC, Leitão AS, Reis TC, dos Santos CS, Coube SG. Screening of Brazilian plant extracts for antioxidant activity by the use of DPPH free radical method. Phytother Res. 2001;15:127-30.

[4] Nordberg J, Arnér SJ. Reactive oxygen species, antioxidants, and the mammalian thioredoxin system. Free Radic Biol Med. 2001;31:1287-312.

[5] Barreiros ALBS, David JM. Estresse oxidativo: relação entre geração de espécies reativas e defesa do organismo. Quím Nova. 2006;29(1):113-23.

[6] Padayatty SJ, Katz A, Wang Y, Eck, P, Kwon O, Lee, JH, Chen S, Corpe C, Dutta A, Dutta SK, Levine M. Vitamin $C$ as an antioxidant: evaluation of its role in disease prevention. J Am Coll Nutr. 2003;22(1):18-35.

[7] Willett WC. Balancing life-style and genomics research for disease prevention. Science. 2002;296:695698.

[8] Steinmetz KA, Potter DJ. Vegetables, fruit, and cancer prevention: a review. J Amer Diet Ass. 1996;96:1027-39.

[9] Maxwell SR. Prospects for the use of antioxidant therapies. Drugs. 1995;49345-61. 
[10] Rahman K. Studies on free radicals, antioxidants, and co-factors. J Clin Interv Aging. 2007;2(2):219-36.

[11] Katalinic V, Milos M, Jukic M. Screening of 70 medicinal plant extracts for antioxidant capacity and total phenols. Food Chem. 2006;94:550-7.

[12] Robards K, Prernzler PD, Tucker G, Swatsitang P, Glover W. Phenolic compounds and their role in oxidative processes in fruits. Food Chem. 1999;66:401-36.

[13] Bouayed J, Bohn T. Exogenous antioxidants - Double-edged swords in cellular redox state. Health beneficial effects at physiologic doses versus deleterious effects at high doses. Oxid Med Cell Longev. 2010;3(4):228-37.

[14] Lu X, Sun D, Wu Q, Liu S, Sun G. Physico-Chemical Properties, Antioxidant Activity and Mineral Contents of Pineapple Genotypes Grown in China. Molecules. 2014;19:8518-32.

[15] Pisoschi AM, Cheregi MC, Danet AF. Total Antioxidant Capacity of Some Commercial Fruit Juices: Electrochemical and Spectrophotometrical Approaches. Molecules. 2009;14:480-93.

[16] Crowe KM, Murray E. Deconstructing a fruit serving: comparing the antioxidant density of select whole fruit and 100\% fruit juices. J Acad Nutr Diet. 2013;113(10)1354-8.

[17] Torres PL. Laboratório on-line de aprendizagem: uma experiência de aprendizagem colaborativa por meio do ambiente virtual de aprendizagem Eurek@Kids. Caderno CEDES. 2007;27:73.

[18] Anastasiou LGC, ALVES LP. Processos de ensinagem na Universidade. Joinville: UNIVILLE, 10 ed. 2012.

\section{Agradecimentos}

Os autores agradecem à Fundação de Amparo à Pesquisa do Estado do Rio Grande do Sul (FAPERGS), Conselho Nacional de Desenvolvimento Científico e Tecnológico $(C N P q)$ e a Coordenação de Aperfeiçoamento de Pessoal de Nível Superior (CAPES), pelos recursos concedidos. 